\title{
Nowcasting of a supercell storm with VERA
}

\author{
Stefan Schneider · Barbara Chimani · Hildegard Kaufmann • \\ Benedikt Bica $\cdot$ Christoph Lotteraner $\cdot$ Simon Tschannett · \\ Reinhold Steinacker
}

Received: 18 January 2008/Accepted: 17 July 2008/Published online: 6 September 2008

(c) The Author(s) 2008. This article is published with open access at Springerlink.com

\begin{abstract}
On 13th May 2003, a severe weather event took place in Vienna, located in the eastern part of Austria at the foothills of the Alps. A supercell storm was reported by storm chasers, including a tornado, large hail and flash floods due to heavy precipitation, causing damage to both people and to goods in parts of Vienna downtown, which is a rather rare event in this region. For this reason, the development of the thunderstorm has been analysed from the synoptic scale down to the storm scale using different data sources, including, e.g. ground measurements, radio soundings and remote sensing data, for a better understanding of the onset and evolution of such a severe weather event. Furthermore, VERA (Vienna Enhanced Resolution Analysis), a real-time analysis system for surface data, was tested on this case study. Measurements which were available during the event have been used to reanalyse the pre-storm situation, testing the possibility of nowcasting such a storm.
\end{abstract}

\section{Introduction}

Thunderstorms are one of the most severe weather phenomena during the summer season in the Alpine region (Houze et al. 1993; Kann 2001), including Austria. Especially along the southern foothills of the Alps, many thunderstorms are reported during the warm season, with a maximum from May to August (Auer et al. 2001). On the northern side of the Alps along the river Danube,

S. Schneider $(\square) \cdot$ B. Chimani · H. Kaufmann · B. Bica

C. Lotteraner $\cdot$ S. Tschannett $\cdot$ R. Steinacker

Department of Meteorology and Geophysics,

University of Vienna, UZA II, Althanstrasse 14,

1090 Vienna, Austria

e-mail: stefan.schneider@univie.ac.at thunderstorms typically develop when a slow moving cold front with a pre-frontal convergence line approaches Austria from the west (Switzerland, Germany), and warm and unstable air is advected from the Mediterranean Sea with south-westerly flow (Kaltenböck 2004).

The thunderstorm which is described in this work developed under such conditions and took place on 13th May 2003 in the region of Vienna downtown. This supercell storm produced a tornado, which is a rather rare event in Austria, with an overall occurrence of 96 reported events ever (Holzer 2001), where the databases contain data back to 1910. Especially in recent years, some efforts for a better documentation of such events have been made by the TorDACH group (http://www.tordach.org/), a network for tornado research in the countries of Germany (D), Austria (A) and Switzerland $(\mathrm{CH})$. Furthermore, the European Severe Weather Database was established, with the main goal of collecting and storing detailed and quality-controlled information on severe weather events over Europe (Dotzek et al. 2006).

Although of rare occurrence, there have been some severe events with tornadoes rated F3 on the Fujita scale (Fujita 1981) and some regions in Austria which are pre-destined for supercell storms with tornadoes have been identified, socalled tornado alleys (Dotzek et al. 1998). The most significant of these alleys within Austria is situated in the eastern part of the country along the river Danube, the region of Vienna and the southern part of Lower Austria, with a probability of 1.2 tornadoes per $10,000 \mathrm{~km}^{2}$ per year (Holzer 2001). The main reasons for the occurrence of this tornado alley is the topography of the region, with the combination of the alpine ridge and the lowlands of the Danube and Hungary, the meeting of cooler and drier air masses from the Atlantic north of the Alps and warmer and moister Mediterranean air masses at the southern side of the Alps, and the occurrence of pre-frontal convergence lines (van Delden 2000). 
The investigations for this paper were focussed on two main aspects. The first deals with the question regarding the possibility of nowcasting such events. One tool which could be useful for this purpose is the objective analysis system VERA, described in Sect. 3. Several of its products available in real time, like the analysis of the mean sea level pressure, the moisture flux divergence or the model comparison, are presented to illustrate the possibilities of this system for the nowcasting of severe weather.

Secondly, the synoptical situation which led to the development of the supercell storm and the outbreak of the tornado which was reported by storm chasers (Eisler and Müller 2003) are described in Sect. 4, using different data sources. These data sources, including, e.g. ground measurements and remote sensing data, are specified in the next section. Furthermore, reports from eyewitnesses have been available for the event.

The paper finishes with some concluding remarks in Sect. 5.

\section{Area of interest and data sources}

\subsection{Area of interest}

The area investigated is located in the eastern part of Austria (Fig. 1). The topography of the region is characterised by the Alps situated in the south-western part with the alpine foothills reaching the area of Vienna, the Bohemian Forest in the north and the lowlands of the river Danube in between. Eastwards, the Hungarian lowland extends. The landscape is inhomogeneous and, therefore, orographic effects play an important role concerning the development and movement of thunderstorms. Greater Vienna is affected by 30 thunderstorms per year on average (Auer et al. 2001), thus, making the region one of the most affected in Austria. During May, about 5 days with thunderstorms and 0.3 days with hail are reported for the period from 1961 to 1990 .

\subsection{Data}

For this case study, different data sources have been used to provide a comprehending overview of the synoptical situation, as well as the relevant processes at the storm scale. The data sources can be divided into in situ data, remote sensing data and model output fields.

Concerning the first group, SYNOP and METAR data from all over central Europe have been used. These surface measurements are provided routinely in real time every 30 min (METAR) or on an hourly basis (SYNOP) and are used for the VERA analysis, described in Sect. 3. Furthermore, radio soundings from Vienna (WMO code 11035), Munich (10868) and Budapest (12843), which are launched twice a day at 00.00 UTC and 12.00 UTC, have been used for the investigation of the vertical distribution of meteorological storm-relevant parameters.
Fig. 1 The area of interest, enclosing the eastern part of the Alps and the valley of the river Danube. Austrian radar sites are marked with circles; the sensors of ALDIS are marked with squares

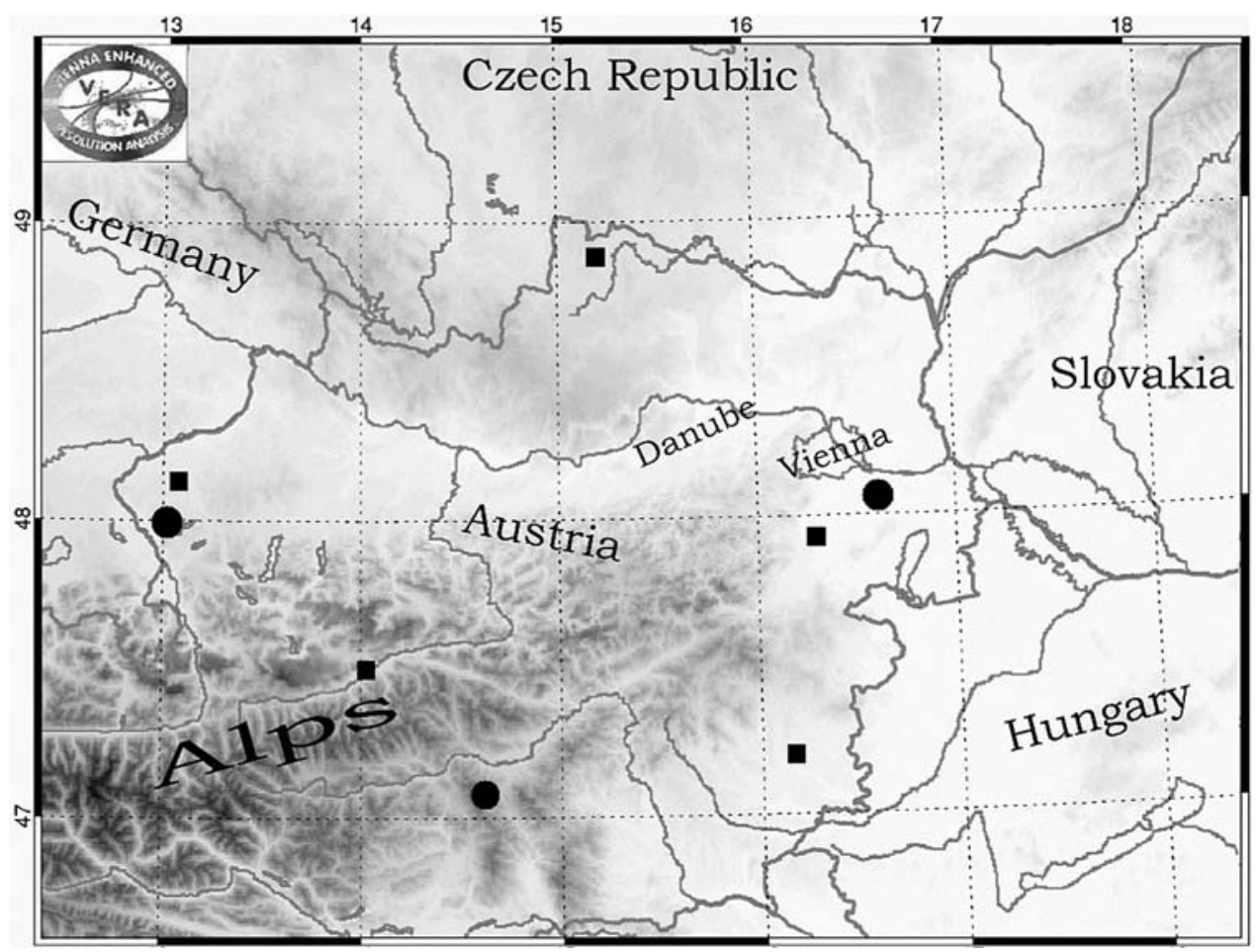


Several remote sensing data sources have been used for the investigations. Radar reflectivity data have been provided by the Austrian Aviation Weather Service (ACG). Four identical Doppler radars which are operating in the $\mathrm{C}$ band at a wavelength of $5.33 \mathrm{~cm}$, with a maximum range of $230 \mathrm{~km}$ and a temporal resolution of $10 \mathrm{~min}$, are in operational use in Austria. The resolution of the data is $1 \times 1 \times$ $1 \mathrm{~km}$, transformed to Cartesian coordinates for the visualisation (Kaltenböck 2004). One of the radars is positioned just a few kilometres away from the place where the storm event took place (Fig. 1).

Lightning data for the event have been provided by the Austrian Lightning Detection and Information System (ALDIS). Eight IMPACT sensors distributed over Austria measure the wave angle and the arrival of lightning strikes (Diendorfer et al. 1992). The range of the detectors is 400 $\mathrm{km}$, which assures that each strike within the Austrian borders is detected by several sensors, providing a detection efficiency of less than $1 \mathrm{~km}$ for the position of each lightning strike.

Model output fields are used for the description of the synoptical situation. Reanalysis charts of the geopotential height and surface pressure and of the temperature at the 850-hPa level from the NCEP, available via the Internet (http://www.wetterzentrale.de), are applied.

The numerical weather prediction forecast charts from the ECMWF have been used to demonstrate the possible applications of the VERA model comparison described in Sect. 3. The spatial resolution of the global ECMWF model is about $40 \mathrm{~km}$; two model runs at $00.00 \mathrm{UTC}$ and 12.00 UTC with a temporal resolution of $3 \mathrm{~h}$ are available for this investigation.

\section{Vienna Enhanced Resolution Analysis (VERA)}

The interpolation method VERA (Steinacker et al. 2000; Pöttschacher et al. 1996) is used for transferring irregularly distributed measurement data to a regular high-resolution grid over complex terrain and was developed at the Department of Meteorology and Geophysics at the University of Vienna. It is intended for application on both scalar and vector quantities. All modules of VERA are running in real time and independently of a weather prediction model or other first-guess fields, using data selfconsistency.

The basic philosophy of VERA is to use the physical a priori knowledge about typical atmospheric structures in the atmospheric boundary layer and lower troposphere over complex topography for downscaling purposes. The analysis can be divided into three different process steps, which are the interpolation step, including the data quality control (Häberli et al. 2004) and the interpolation on a regular grid
(Steinacker et al. 2000), the downscaling step using the fingerprint technique (Steinacker et al. 2006) and the post processing to calculate additional parameters, such as the moisture flux convergence.

\subsection{Data quality control}

In contrast to other operational quality control procedures, there is no need to deal with any first-guess fields or with physical or climatological limits at the beginning when using the VERA quality control. The method is used with a decision-making algorithm to find out how strong the effect of calming down (minimisation of curvature) of the surface can be achieved by changing the value of one single station value. Hence, a deviation value for each station is calculated successively and each term can be further investigated statistically to discover gross errors, biasses, mesoscale signals and the meteorological noise occurring at every single station.

\subsection{Interpolation method}

This method is based on the variational principle applied to higher order spatial derivatives, which are computed from overlapping finite elements (Steinacker et al. 2000). For any scalar quantity $P$, the cost function $J(P)$ as the weighted sum of the squared spatial derivatives on two dimensions is minimised:

$J(P)=\iint_{\sigma} \sum_{i} \gamma_{i}\left[S D_{i}(P)\right]^{2} \mathrm{dxdy} \rightarrow \min$

where $\gamma_{i}$ stands for the weight of the different $(i)$ spatial derivatives $S D_{i}$ and $\sigma$ denotes the area of the finite elements used for the derivation. This method minimises the curvature and/or gradient of scalar fields and the kinematic quantities of vector fields, respectively. It is equivalent to the penalty function of thin-plate smoothing splines (Daley 1991).

\subsection{Downscaling}

Due to the irregular spacing and, especially in mountainous regions, the sparse density of real-time observations and their specific situation with respect to topography (i.e. stations in valleys or basins, on slopes, on passes, on mountain tops), the analysed field may be quite rough. Consequently, small-scale structures produced by topography cannot be sufficiently resolved by conventional analysis schemes, which tend to treat this roughness as noise and smooth it out. But mountainous topography actually produces small-scale structures of considerable amplitudes. The modification of the atmosphere by a mountain massif (e.g. Whiteman 2000) can be split up into 
two different physical processes, into thermal effects due to different heating or cooling of the atmosphere over mountains (e.g. thermal low or thermal high over the Alps, Bica et al. 2007) and into dynamic influences, such as blocking or leeside effects. These features of the mountainous atmosphere, called "fingerprints" (Steinacker et al. 2006), may be modelled at scales far below that resolved by observations, if a very high resolution topographic data set is available. The modelled thermal and dynamic fingerprints are finally used to fit the observations locally (again, the derivatives) by a mean square method. Such fingerprints are similar to EOFs; however, they are being physically determined instead of statistically.

In a first step, for each type of physical processes forced by topography, an idealised fingerprint is computed from a high-resolution (approximately 1-km) topographic data set. For the analysis, individual observations determine the local intensity of the thermal and/or dynamic topographic fingerprint. For analyses shown in this paper, three fingerprints have been used, one for the thermally induced field and two for blocking and leeside effects.

\subsection{Model comparison}

The horizontal resolution of current operational large-scale NWP models (7-40 km) is still too coarse to compare single values of surface stations, especially over complex terrain with nearby model grid points. In addition, the modelanalysed fields do not represent an independent source for evaluating a model run, since they represent mainly the first-guess field in data-sparse areas. The analysis tool VERA fits this gap (Dorninger et al. 2004). Since the VERA parameters, such as potential temperature and equivalent potential temperature, are not standard model output parameters, they are calculated from the appropriate model parameters from the model surface or from the lowest model level, respectively (see Fig. 2). Two different methods for the comparison of the pressure field are in use. The reason for these two comparisons is the fact that different reduction methods are in use for VERA and the forecast models. To satisfy the needs of the model, the standardised reduction is sometimes replaced by a modified method for suppressing structures in the pressure field due to thermal effects (heat low, cold high). This leads to significant differences between VERA analyses and forecast fields, especially in mountainous regions like the Alps. On the one hand, the mean sea level pressure as a model output is compared; on the other hand, a reduction of the pressure field of the lowest model level to the sea level by standardised reduction methods is calculated first and is then compared. Of course, the height of the lowest model level above the mean sea level has to be known. The advantage of the version using the pressure data of the lowest model level
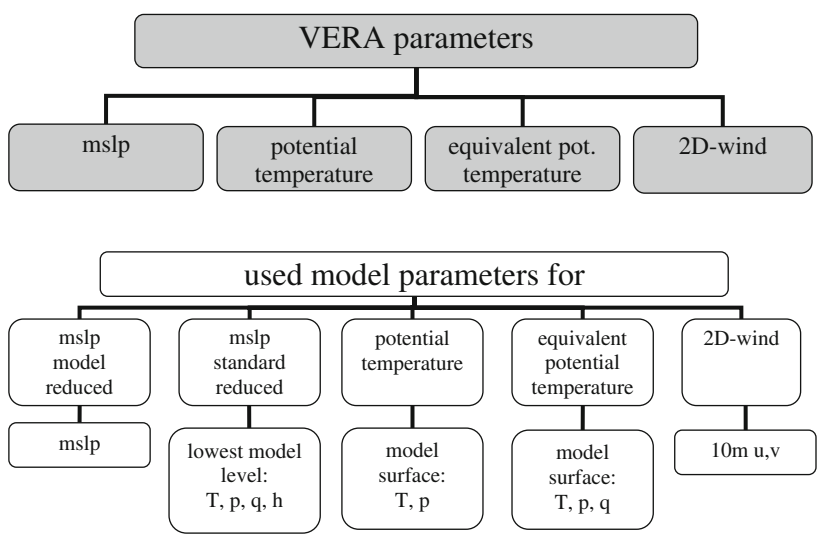

Fig. 2 Parameters analysed in the current VERA version and used for the model comparison (upper panel) and the used numerical weather prediction (NWP) model fields to calculate the VERA parameters (lower panel). $T=$ temperature, $p=$ pressure, $q=$ specific humidity, $m s l p=$ mean sea level pressure, $u, v=$ horizontal components of the wind field, $h=$ height of the lowest model level above the model topography

to reduce them to the mean sea level by common reduction methods is the fact that the model data can be compared to the VERA data of the mean sea level pressure without receiving artefacts due to the different reduction methods.

In a second step, the model data are interpolated to the VERA grid by using the Cressman approach (Cressman 1959). This simple interpolation method is appropriate, since the resolution of the used NWP models is similar to the VERA grid resolution. The choice of the Cressman radius is model-dependent; the denser the model grid, the lower the influence radius for the calculation. This method assures that, for each model under investigation, the number of grid points which are taken into account for the interpolation to one VERA grid point is rather similar. Otherwise, a difference field with noisy structures would be the result of the model comparison.

In a final step, the differences between the VERA topography and the model topography are taken into account by using the standard atmosphere for the vertical interpolation.

The resulting fields (difference fields between model forecasts and VERA analyses) serve as an early recognition system to identify differences between analysis and model forecast, allow for a monitoring of the differences and give the forecaster a decision tool to judge the further model forecast. Furthermore, a statistical interpretation of the data may lead to the knowledge about problems in the model performance.

\subsection{Moisture flux divergence}

For calculating the moisture flux divergence, the VERA output fields for the $10-\mathrm{m}$ wind, the potential temperature 
$(\Theta)$ and the equivalent potential temperature $\left(\Theta_{\mathrm{e}}\right)$ are used. For each of the $20-\mathrm{km}$ grid points, a moisture flux divergence value is computed, whereas the wind field can be used without any further post processing. As a humidity quantity, the mixing ratio has been chosen (Bothwell 1988; Beckman 1993), calculated from the equivalent potential and potential temperature fields, using the following considerations. Starting with the equivalent potential temperature (e.g. Bergmann and Schaefer 1997):

$\Theta_{\mathrm{e}}=\Theta \exp \left(\frac{L m}{c_{p} T}\right)$

and taking into account that the exponent results in small values for latent heat $L \sim 10^{6} \mathrm{~J} \mathrm{~kg}^{-1}$, mixing ratio $m \sim$ $10^{-3} \mathrm{~g} \mathrm{~kg}^{-1}$, specific heat $c_{p} \sim 10^{3} \mathrm{~J} \mathrm{~kg}^{-1} \mathrm{~K}^{-1}$ and temperature $T \sim 10^{2} \mathrm{~K}$, the approximation of $\mathrm{e}^{x}=1+x$ for small $x$ can be used for Eq. 2. This leads to:

$\Theta_{\mathrm{e}}=\Theta+\frac{L m}{c_{p}} \frac{\Theta}{T}$

Furthermore, the ratio of $\Theta T^{-1}$ is approximately equal to 1 near the surface, and so, the mixing ratio results in:

$m=\left(\Theta_{\mathrm{e}}-\Theta\right) \cdot 0.402 \times 10^{-3}$

for $L=2.5 \times 10^{6} \mathrm{~J} \mathrm{~kg}^{-1}$ and $c_{p}=1,005 \mathrm{~J} \mathrm{~kg}^{-1} \mathrm{~K}^{-1}$ (Kaufmann 2006). With the mixing ratio $m$ and the twodimensional wind field $V_{\mathrm{h}}=(u, v)$, the moisture flux divergence can be calculated as:

$\nabla_{\mathrm{h}} \cdot m V_{\mathrm{h}}=V_{\mathrm{h}} \cdot \nabla_{\mathrm{h}} m+m \nabla_{\mathrm{h}} \cdot V_{\mathrm{h}}$

with the moisture advection as the first term on the righthand side of Eq. 5 and the moisture divergence as the second term of the equation, with $\nabla_{\mathrm{h}}$ as the nabla operator.

A scale analysis (Banacos and Schultz 2005) for both terms proves that the advection term is the dominant one for synoptic-scale features. For mesoscale boundaries, horizontal mass convergence is larger, implying the dominance of the divergence term.

There have been several investigations, especially in the United States, which are showing that the moisture flux divergence can be used for the prediction of convergence (e.g. Hudson 1971; Negri and Vonder Haar 1980; Hirt 1982) in the nowcasting range and also for the investigation of thunderstorms and tornadoes (van Delden 2001).

A good overview is given by Bothwell (1988), pointing out several aspects which have to be taken into account when using the moisture flux divergence. To initiate convection, an area of moisture flux convergence is necessary for several hours; it is strongly scale-dependent and, especially during the night, the ground field of convergence is not representative for processes at higher levels. Furthermore, there is no magic number for the intensity of moisture flux convergence which guarantees for convergence and, in many cases, the change of the convergence with time is more important than the absolute value. Moreover, the pattern of the moisture flux convergence can give an indication on the developing system; for example, circular patterns are often connected to supercells.

\section{Discussion of the storm event}

\subsection{Synoptic situation}

The synoptic situation in the days before the event was characterised as a low-index situation with a significant trough, situated over Iceland, with the axis over the eastern Atlantic, moving slowly eastwards. On the western and southern side of the trough, cold maritime air from the Arctic was advected towards Europe in several steps, leading to cold fronts moving over central Europe. The temperature at the $500-\mathrm{hPa}$ level was down to $237 \mathrm{~K}$ at the centre of the low-pressure system on 10th May 2003. The corresponding surface flow with a core pressure of 998 $\mathrm{hPa}$ was situated south of Iceland on this day and the connected frontal system was already occluding. The occlusion front was situated over the North Sea and Great Britain, extending towards the Azores.

The low-pressure system was just moving slowly to the east; nevertheless, the system influenced central Europe due to several short-wave troughs embedded in the main trough, leading to convective precipitation in large parts of central Europe, including Austria. In the upper levels, at the front side of the trough, warm and moist air masses from the Mediterranean Sea were advected towards the Alpine region, which enforced the convection.

Figure 3 shows the situation on 12th May 2003 at 00.00 UTC. In grey shades, the geopotential height at the $500-\mathrm{hPa}$ level is denoted, with the trough axis situated over Great Britain and France. Also, the south-westerly flow towards the Alps can be seen. The Vienna radio sounding from 00.00 UTC reports 20 knots wind speed at the $500-\mathrm{hPa}$ level. At the ground level, the pressure distribution is characterised by the white isolines. The surface lowpressure system is situated between Iceland and Scotland, with a core pressure of $1,003 \mathrm{hPa}$. In central Europe, the pressure distribution shows very weak gradients. The cold front, which became interesting for the supercell storm in Vienna, is situated over Denmark and Germany, leading to convective precipitation in these regions.

\subsection{Pre-storm conditions}

On 13th May 2003, the radio sounding of Vienna at 00.00 UTC (Fig. 4a) shows a weak inversion, establishing during the night due to the very weak wind at the ground level, 
Fig. 3 Reanalysis of the geopotential height at $500 \mathrm{hPa}$ (grey shades, unit $=$ geopotential metres) and the surface pressure field in $\mathrm{hPa}$ (white isolines) from the NCEP for 12th May 2003 at 00.00 UTC (from http://www. wetterzentrale.de)

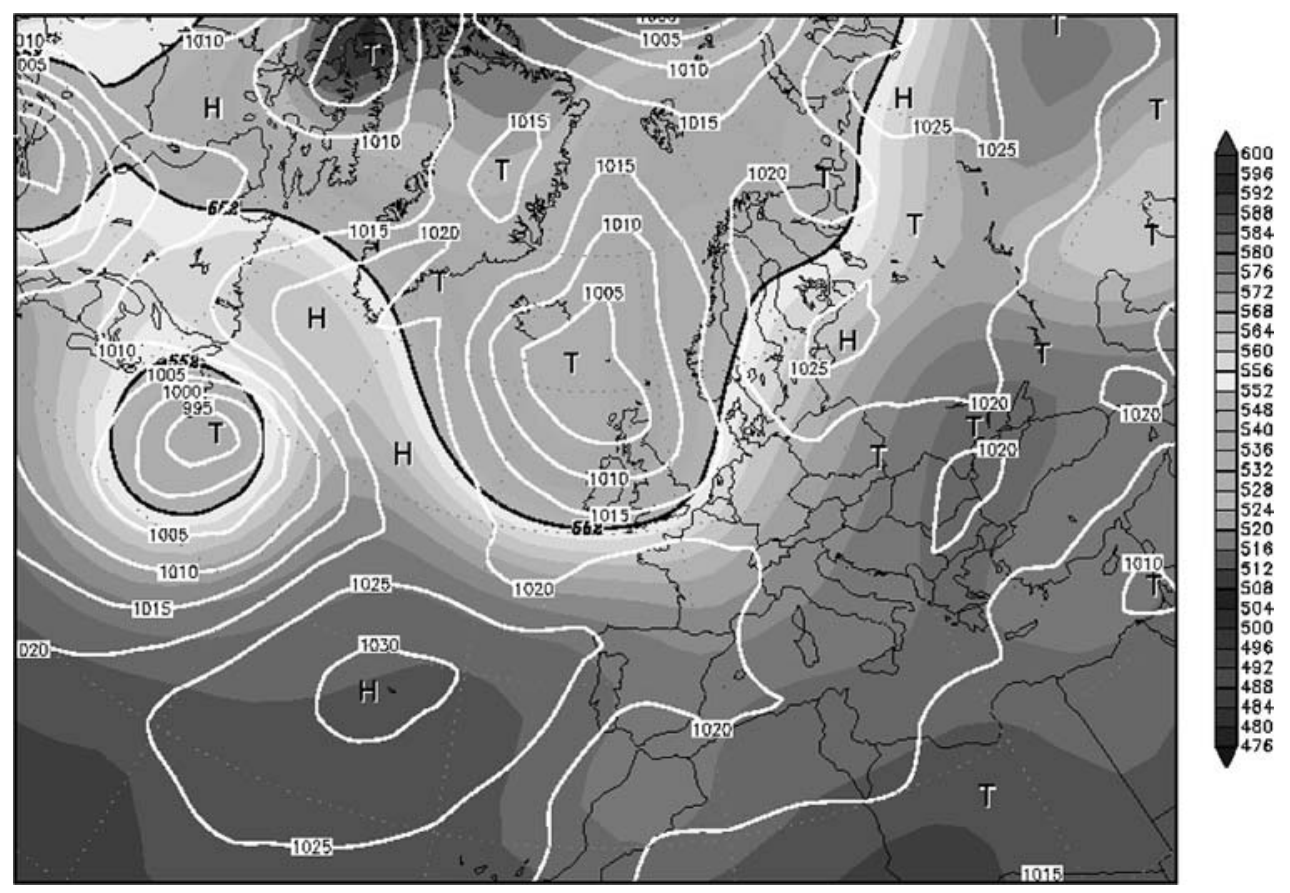

(a)

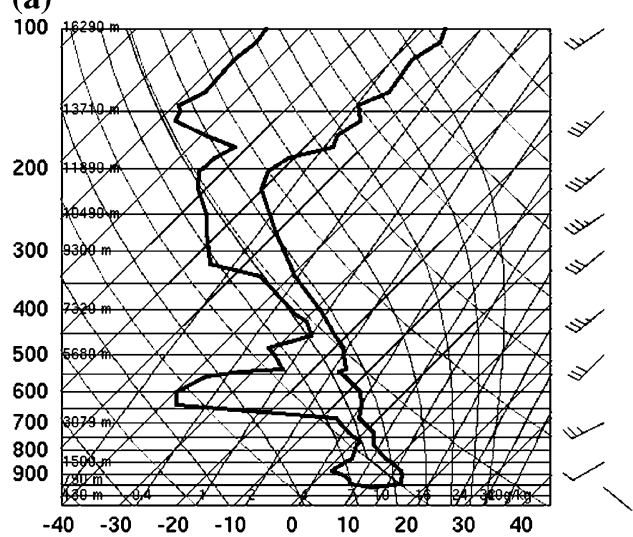

(c)

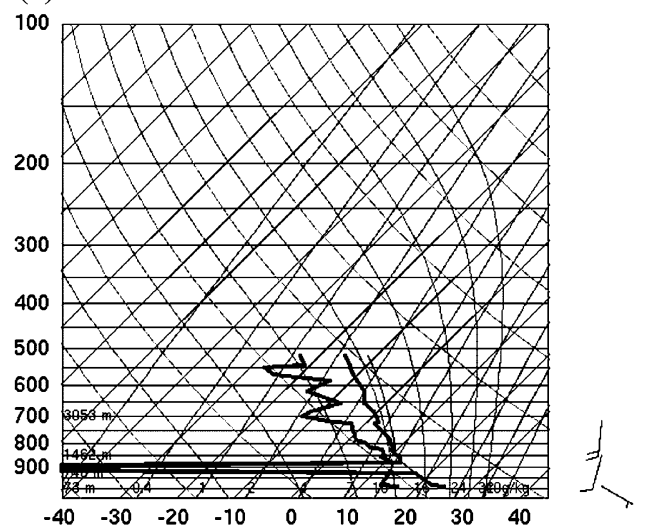

(b)

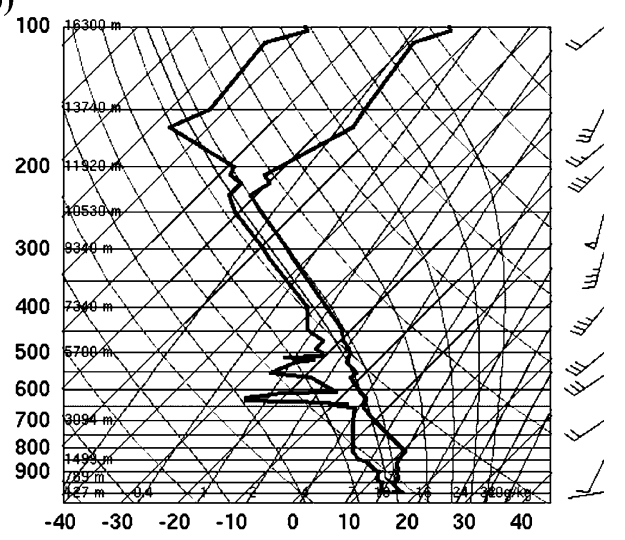

Fig. 4 Skew- $T$ diagrams of radio soundings for Vienna (a) 13th May 2003 at 12.00 UTC (c) (from the University of Wyoming). The temperature in ${ }^{\circ} \mathrm{C}$ is given on the abscissa; the pressure in $\mathrm{hPa}$ is given on the ordinate. The thick black lines show the temperature and dew point of the radio sounding, and the wind feathers indicate the wind speed in knots for significant levels and a thin moist ground layer. The vertical wind profile with south-westerly flow at higher levels shows a wind shear with height, which is necessary for the development of thunderstorms. Doswell and Evans (2003) found that the median value of the surface to $6 \mathrm{~km}$ above ground level shear near supercells is slightly above $20 \mathrm{~m} \mathrm{~s}^{-1}$. For 
Vienna, the value was about $15 \mathrm{~m} \mathrm{~s}^{-1}$ at 00.00 UTC. Parameters for convection, such as CAPE $\left(22 \mathrm{~J} \mathrm{~kg}^{-1}\right)$ and the lifting index (1.33), were showing low values at that moment, which is not surprisingly for that time of day.

To initiate the convection, usually, an additional source of lifting is required. At the northern foothills of the Alps, pre-frontal convergence lines are often responsible for this additional synoptic forcing (Kaltenböck 2004). Such a convergence line was also responsible for the development of convection on 13th May. The position of the convergence line can be seen in the VERA analysis for 00.00 UTC in Fig. 5. Such analysis charts are available for the forecaster every hour. Meteorological stations which provide data for the analysis are indicated with squares (wind), crosses (pressure) and diamonds (equivalent potential temperature) in the graphic. The area which is analysed routinely covers the whole alpine region, with Austria and Switzerland in the centre of the chart. The black isolines represent the mean sea level pressure field, the colour shades indicate the equivalent potential temperature and the $10-\mathrm{m}$ wind is indicated by arrows.

During the night, a cold high was developing over the central alpine ridge, with the maximum situated at 00.00 UTC over eastern Switzerland. A secondary pressure maximum can be seen along the Dalmatian Mountains. North of the Alps, a shallow pressure distribution, resulting in low wind speeds at that time, was present. The convergence line was situated over Bavaria, with easterly winds in front of the convergence line due to the outflow of the alpine valleys and stronger westerly winds behind this line. The cold front was situated over France according to the equivalent potential temperature and the weak trough in the pressure field. Air masses with higher energy were situated in Hungary, the Po Valley in northern Italy and in the Vienna region, with values up to $316 \mathrm{~K}$.

Figure $4 \mathrm{~b}$ shows the radio sounding for Munich on 13th May 2003 at 00.00 UTC. Munich was then near the convergence line with weak easterly wind at the ground, an inversion of $4 \mathrm{~K}$ near the ground and dry air intrusion above the 700-hPa layer. A comparison of the temperature at the upper levels between Stuttgart (WMO code 10739), Munich (10868), Vienna (11035) and Budapest (12843) shows a difference of only $2 \mathrm{~K}$ in the 500-hPa layer, while at the $850-\mathrm{hPa}$ level, the difference is much bigger. Stuttgart, already situated already in the cold air, reports 281.35 $\mathrm{K}$, Munich at the convergence line $282.95 \mathrm{~K}$, Vienna $(284.15 \mathrm{~K})$ and Budapest $(286.75 \mathrm{~K})$ are still in the warmer air mass.

As the focus of the investigation lays in the region north of the Alps, the following VERA analysis charts are displayed just for that region. Figure 6a shows the condition for 09.00 UTC on 13th May 2003. Again, the three parameters, mean sea level pressure, equivalent potential temperature and the 10-m wind field, are displayed. The convergence line was then already situated over Austria and the Czech Republic. Eastwardly, south-easterly winds dominated at the ground level due to a shallow highpressure system over Hungary, while at higher levels, the south-westerly wind remained over Vienna. There, the equivalent potential temperature reached a value of $325 \mathrm{~K}$ at that time, while the pressure decreased by $3.5 \mathrm{hPa}$ during the previous $9 \mathrm{~h}$. The cold front was situated on the
Fig. 5 VERA analysis for 13th May 2003 at 00.00 UTC. The black isolines indicate the mean sea level pressure in steps of 1 $\mathrm{hPa}$, the colour shades represent the equivalent potential temperature in ${ }^{\circ} \mathrm{C}$ (reddish $=$ high, bluish $=$ low equivalent potential temperature) and the arrows indicate the $10-\mathrm{m}$ wind field. Measuring stations are represented by squares, diamonds and crosses. $H$ and $L$ indicate high- and low-pressure systems, respectively

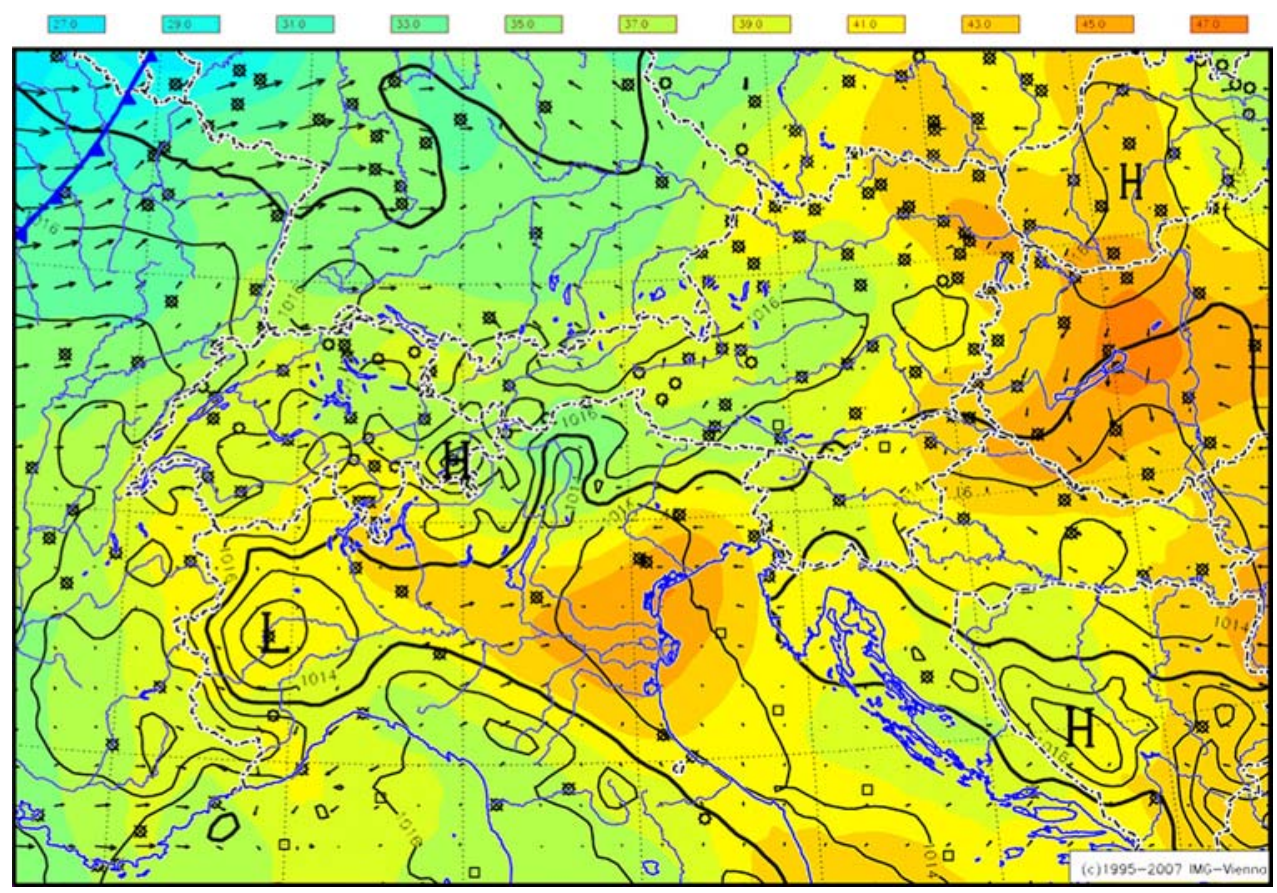


German-Czech border in the north to the Alpine foothills of Switzerland and western Austria, blocked by the Alpine ridge so that the warm and moist air masses from the Mediterranean Sea could still be advected to Vienna on the southern side of the Alps without any disturbance due to the cold front. Because of the advection of warm air at higher levels and the large energy consumption for evaporation due to the precipitation in the Vienna region on the previous day, convection was inhibited during the first half of the day.

To get the feeling of how well the actual situation is represented by the models, the VERA model comparison can be used. The difference fields which are calculated, as well as the analyses, are available in real time and can be used for deciding which model will give the most adequate forecast for the next few hours in the area of interest. As an example, the difference field for the equivalent potential temperature between VERA and the ECMWF model for 09.00 UTC is displayed in Fig. 6b. The model run started at 00.00 UTC on that day, so the displayed field shows the 9-h forecast. Positive (negative) deviations indicate that the values of the equivalent potential temperature are higher (lower) in the VERA analysis than in the ECMWF model.

The position of the cold front is represented quite well at that time, whereas the temperature of the air mass advected with the cold front is underestimated in the weather prediction model, with the model being warmer by up to $6 \mathrm{~K}$ in some parts of Bavaria. Deviations of the same magnitude can be seen in the region of Vienna. Over the alpine ridge and in the Po Valley, positive deviations (the analysis shows higher values than the model) were occurring, whereas significant deviations over the central Alps are quite common in the model comparison due to local effects which cannot be resolved by the ECMWF model (grid resolution about $40 \mathrm{~km}$ ) and to the significant differences in the topographies used during the calculation of the model and the analysis. For the wind field displayed in Fig. 7, the differences between the VERA analysis and the model output both in intensity and direction can be seen. Again, for comparison, the 9-h forecast of the ECMWF model was used. Especially in the region of the convergence line, significant differences can be seen. The convergence line is not that pronounced in the model forecast, with wind speeds much lower in eastern Austria and Slovakia and it is positioned further in the east, indicating that the convergence line would pass Vienna faster than in reality and, thus, not be as effective for the triggering of convection.

The moisture flux divergence calculated for this day shows negative values, meaning that convergence, for central lower Austria from 06.00 UTC onwards, increases continually until, at $10.00 \mathrm{UTC}$, the analysis of the moisture flux divergence gives the first significant signal for the development of convection in the Vienna region (values up

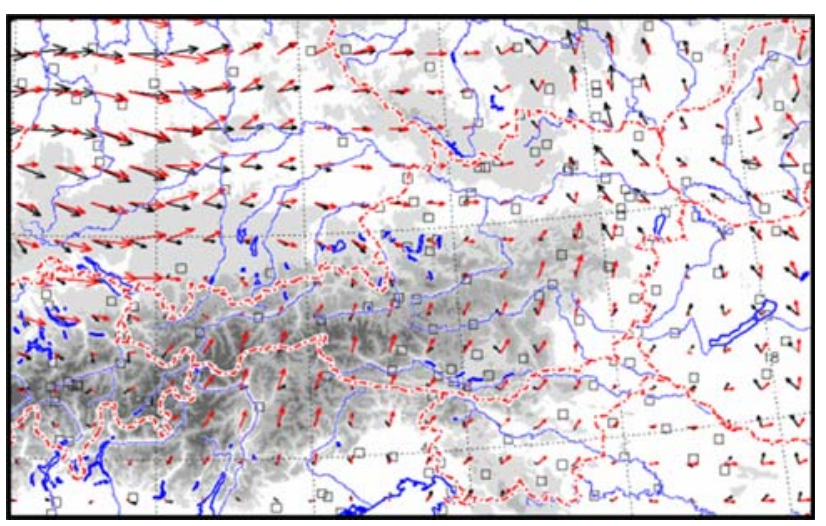

Fig. 7 Model comparison for the 9-h forecast of the 10-m wind field from the ECMWF model (red arrows) with the VERA analysis (black arrows) for 13th May 2003 at 09.00 UTC. Deviations are significant in the area of the convergence line where the wind speed is much higher in the VERA analysis. Furthermore, the position of the convergence line is shifted to the east in the model (a)

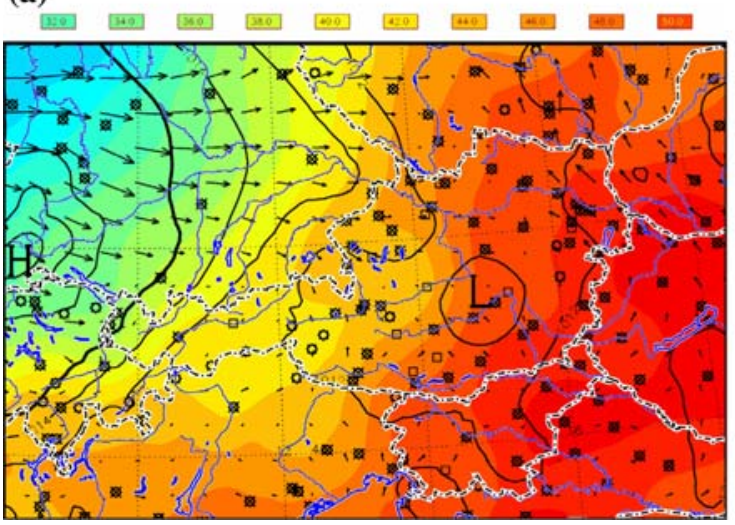

Fig. 6 VERA analysis (a) and model comparison (b) between VERA and ECMWF for the equivalent potential temperature on 13th May 2003, 09.00 UTC. In areas with negative deviations (bluish colour (b)

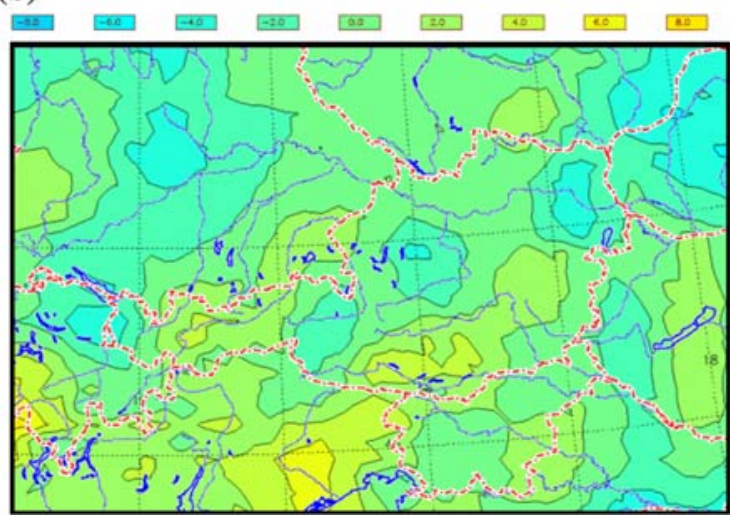

shades), the equivalent potential temperature in the VERA analysis is lower than in the 9-h forecast of the ECMWF model, and vice versa 
to $-8 \times 10^{-4} \mathrm{~g} \mathrm{~kg}^{-1} \mathrm{~s}^{-1}$ ) and also further in the north over the Czech Republic (values up to $-10 \times 10^{-4} \mathrm{~g} \mathrm{~kg}^{-1} \mathrm{~s}^{-1}$ ) along the convergence line. Due to the topography in this region, the convergence line propagated faster in the lowlands along the river Danube than over the hilly terrain to the north, which can be seen in the wind field in Fig. 8a. Regions with ongoing moisture flux convergence over several hours are predestined for convection (Bothwell 1988), and within the region of the moisture flux convergence area, the easterly quadrant is supposed to be the preferred area of convection (Hirt 1982). Both parameters for the prediction of convective developments indicate that the Vienna region could be affected by convective events on that day. Furthermore, the circular structure of the moisture flux divergence pattern indicates that a supercell storm could be developing (Bothwell 1988).

Following the suggestion of Banacos and Schultz (2005), the surface horizontal divergence was calculated for the same date (displayed in Fig. 8b), showing similar spatial patterns to the moisture flux convergence, but with absolute values of about one magnitude lower. For the forecaster interested in just the pattern for detecting hot spots, horizontal divergence might be suitable. As moisture is known as one of the major ingredients for convective processes, moisture flux divergence should be preferred for scientific investigations nevertheless, as, in detail, there are differences in the local pattern between pure divergence and moisture flux divergence.

Being nearly stationary until this time, $1 \mathrm{~h}$ later at 11.00 UTC, the maximum of the moisture flux convergence had moved to the east, and a secondary maximum developed north of the Danube, displayed in Fig. 9. Convection had already started at that time in eastern Austria, and at 12.00 UTC, the convergence line further forced the dynamic penetration of the inversion by the moisture-laden air at the eastern foothills of the Alps. The flow of air masses with high equivalent potential temperature around the eastern edge of the Alps can be seen in Fig. 10, as well as the approaching cold front from the northwest. In the area eastward of Vienna, the highest values for the equivalent potential temperature on that day within the greater alpine region were calculated with a maximum of $333 \mathrm{~K}$ and in Vienna, $330 \mathrm{~K}$ was analysed, which is an increase of $14 \mathrm{~K}$ in $12 \mathrm{~h}$. The cold front was, at that moment, situated along the German-Austrian border and was due to the blocking by the mountain ridge along the northern side of the Alps. At the south-western end of the Alps (not displayed), the high wind speeds and the low equivalent potential temperature indicate that the cold air had already reached the Mediterranean Sea, where the conjunction of the different air masses triggered a cyclogenesis over the Gulf of Lyon during the next day.

Looking at the pressure distribution of the VERA analysis in Fig. 10, the building of a meso-low north of Vienna due to diabatic heating was of importance for the further development of the storm, as this structure slowed down the movement of the convergence line, enforcing the convection. In Vienna, the pressure had decreased again by $2 \mathrm{hPa}$ within the last $3 \mathrm{~h}$.

This meso-low north of Vienna, as well as the meso-low over the eastern Alps, was not predicted in the ECMWF forecast, which can be seen in the model comparison in Fig. 11. Again, the model output is from the 00.00 UTC run of 13th May, being a 12-h forecast. The differences north of Vienna ( $-2 \mathrm{hPa})$ and over the eastern Alps $(-3 \mathrm{hPa})$, with negative deviations all along the cold front suggest that the intensity of the cold front was not well predicted by the model. Over Bavaria, the deviations are positive, giving a dipole structure which is typical for a case where the pressure gradient at the cold front is weaker in the (a)

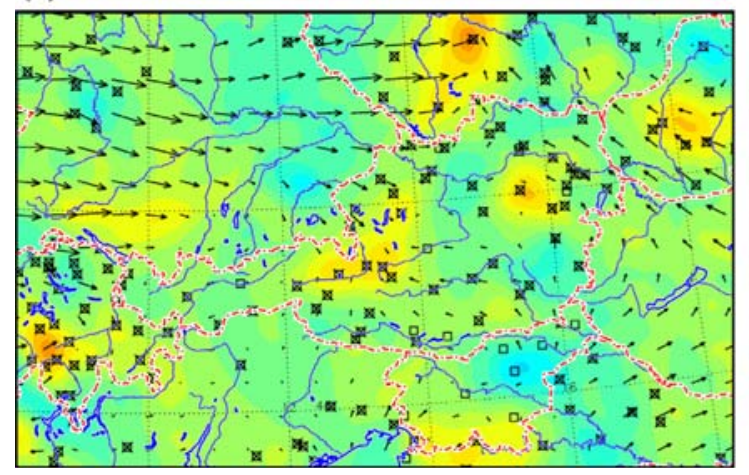

Fig. 8 a Moisture flux divergence (bluish colour shades; convergence in reddish colours) and 10-m wind field for 13th May 2003, 10.00 UTC. Stations used only for analysing the wind field are indicated by squares and stations which were used for the calculation of the moisture flux divergence are indicated by crosses. Maximum (b)

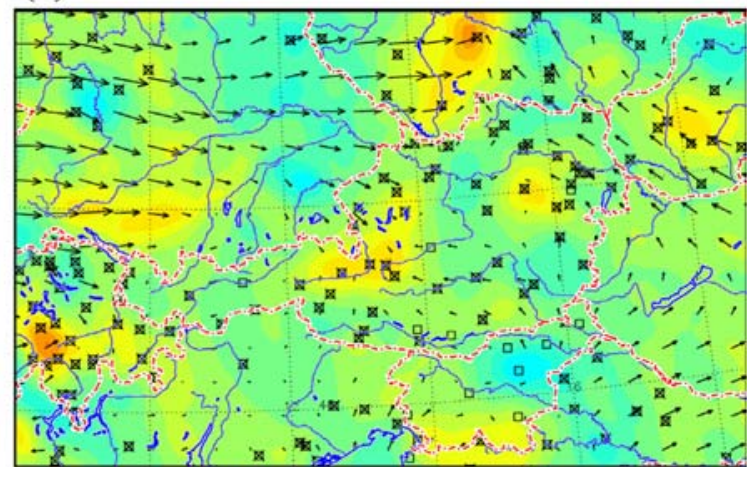

wind speeds are $6 \mathrm{~ms}^{-1}$ in the area displayed, the moisture flux divergence ranges from $-10.13 \times 10^{-4}$ to $+8.57 \times 10^{-4} \mathrm{gkg}^{-1} \mathrm{~s}^{-1}$. b For the same date, the surface horizontal divergence is plotted. The colour codes and arrows are as in (a), but with values for the divergence ranging from $-15.32 \times 10^{-5}$ to $+9.75 \times 10^{-5} \mathrm{~s}^{-1}$ 
Fig. 9 The same as Fig. 8a but for 11.00 UTC. Maximum wind speeds are $6.3 \mathrm{~ms}^{-1}$ in the area displayed, the moisture flux divergence ranges from -13.12 $\times 10^{-4}$ to $+8.34 \times 10^{-4} \mathrm{gkg}^{-1}$ $\mathrm{s}^{-1}$. The unit of the caption is $10^{-4} \mathrm{gkg}^{-1} \mathrm{~s}^{-1}$
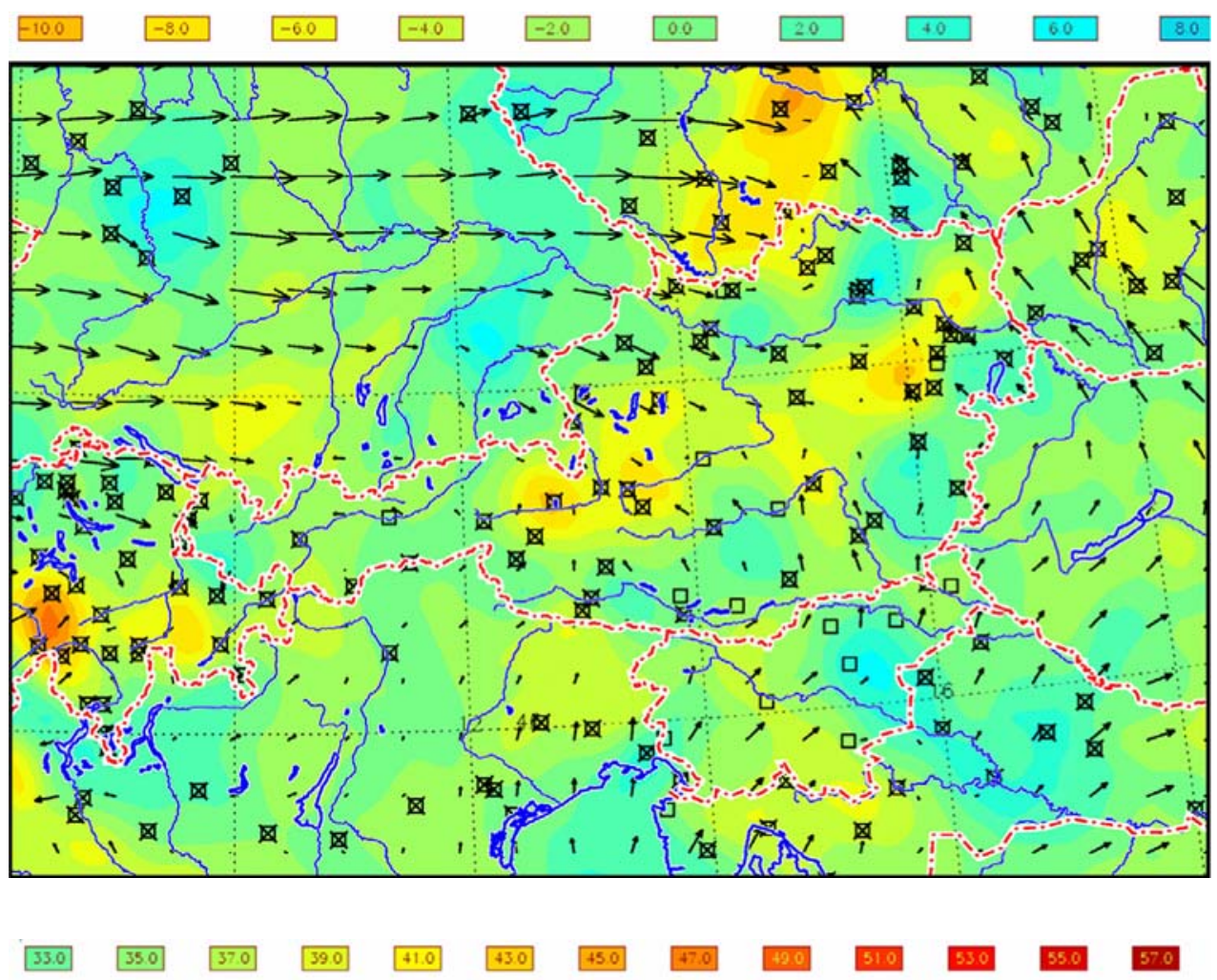

Fig. 10 Same as Fig. 5 but for 12.00 UTC. The unit of the caption is ${ }^{\circ} \mathrm{C}$

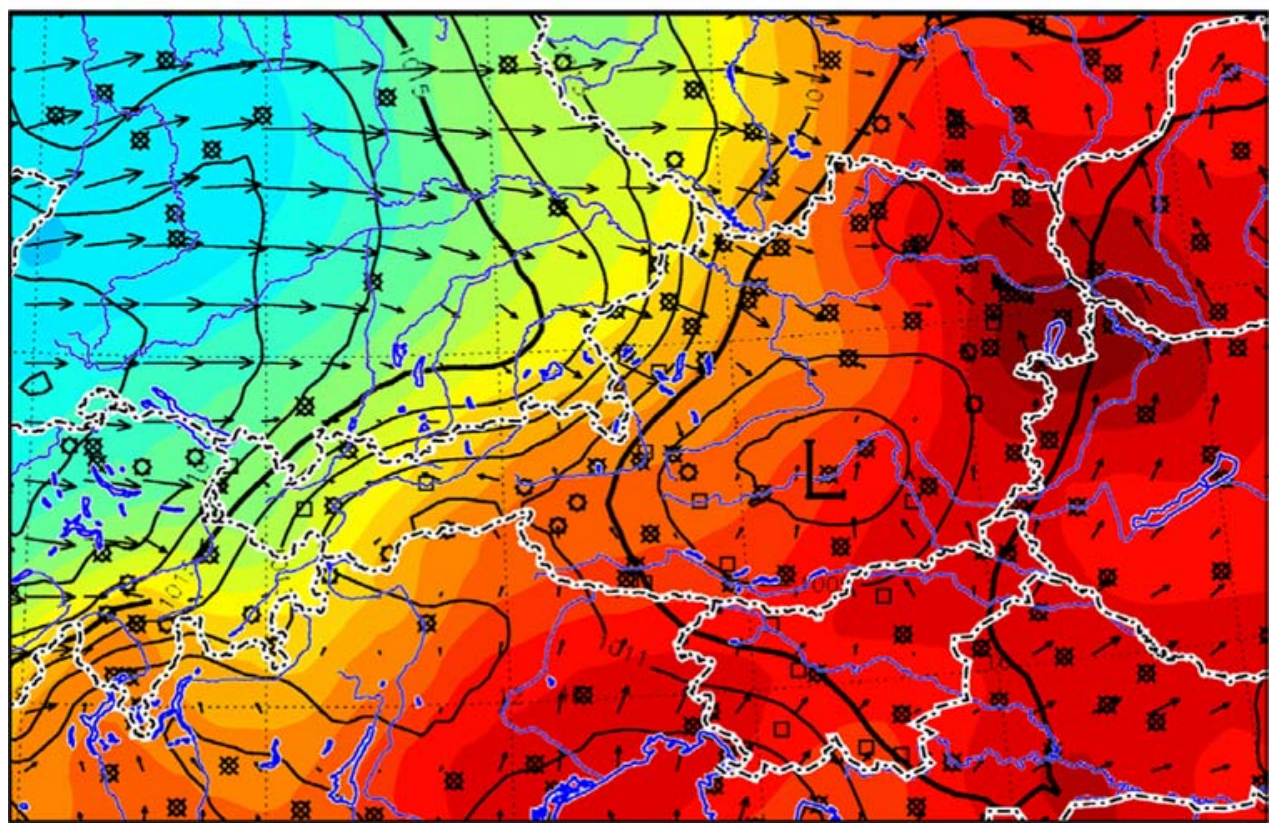

model than in the analysis, which is valuable information for the forecaster using the model output for nowcasting.

At 12.00 UTC, the storm had already developed and, in the west of Vienna, the first thunderstorm was reported in the SYNOP report of Tulln (WMO code 11030), $15 \mathrm{~km}$ northwest of Vienna. Unfortunately, the radio sounding from Vienna at 12.00 UTC (Fig. 4c) just reached the 550$\mathrm{hPa}$ level before. Additionally, there were some erroneous measurements near the ground. Nevertheless, one can see the over-adiabatic ground layer with easterly winds and the southerly flow in higher levels and the latent instability (Galway 1956; Groenemeijer 2005). CAPE, calculated from a parcel from the lowest $500 \mathrm{~m}$ of the atmosphere, raised dry adiabatically to the LCL and moist adiabatically thereafter, is about $1,200 \mathrm{~J} \mathrm{~kg}^{-1}$ compared to a CAPE of approximately $1,500 \mathrm{~J} \mathrm{~kg}^{-1}$ calculated from the model data. The temperature at the $850-\mathrm{hPa}$ level $(283.15 \mathrm{~K})$ was nearly the same as at 00.00 UTC but the equivalent 


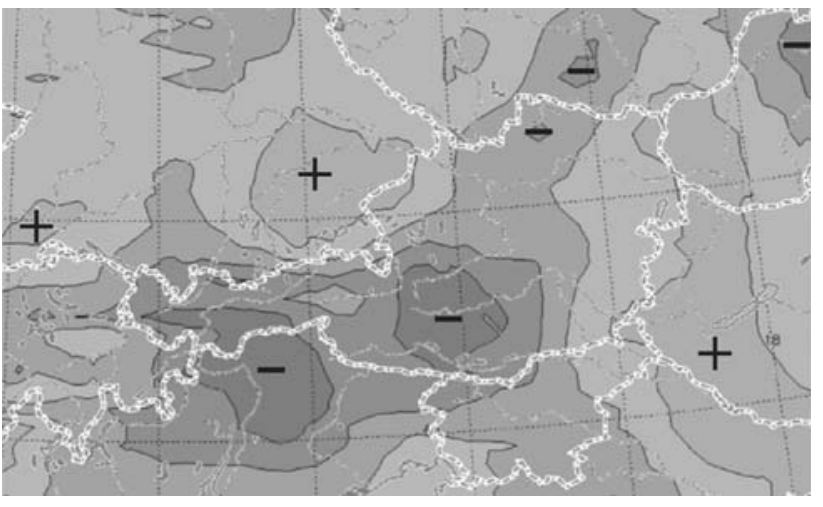

Fig. 11 Model comparison between the VERA analysis (12.00 UTC) and the 12-h forecast of the ECMWF (model run from 13th May 2003, 00.00 UTC) for the mean sea level pressure (reduced by common reduction methods). Negative (positive) values marked with - (+) indicate that the pressure is lower (higher) in the VERA analysis than in the model. The interval of the isolines is $1 \mathrm{hPa}$

potential temperature rose from 315.7 to $322.7 \mathrm{~K}$ during the $12 \mathrm{~h}$. In the radio sounding of Munich, the cold air had already reached the $850-\mathrm{hPa}$ level, with a decrease of the temperature of $4.4 \mathrm{~K}$ and of the equivalent potential temperature of $5.3 \mathrm{~K}$ in $12 \mathrm{~h}$ at the $850-\mathrm{hPa}$ level.
Until 13.00 UTC, the supercell reached Vienna downtown, moving in from the northwest. Using the data of the Austrian radar composite with one of the radars positioned near Vienna airport, vertical (Fig. 12a, b) and horizontal (Fig. 12c, d) cross sections can be studied. The vertical axis of the supercell is tilted towards the southeast, with a maximum reflectivity of between 5 and $10 \mathrm{~km}$ in height, which is typical for the mature stage of a thunderstorm cell. The maximum reflectivity is more than $55 \mathrm{dBz}$, which is attributed to hail (Waldvogel et al. 1978), which really did occur during this event.

In the horizontal cross sections, specific features in the reflectivity pattern indicate rotating updrafts and supercell storms (see, e.g. Burgess and Lemon 1990). In the case investigated, a hook-echo can be detected (Fig. 12c) at a height of $2.5 \mathrm{~km}$. Doppler-radar studies indicate that the hook echo is associated with large horizontal shear and/or a mesocyclone (Forbes 1981), therefore, it is an indicator often used for supercells, although the relation is not distinct. In the radar velocity field (Fig. 12d) for 13.00 UTC (Kaltenböck 2005), the rotation of the cloud in the Vienna region is also identifiable. Both of these components, already detected $30 \mathrm{~min}$ before the reported touchdown of
Fig. 12 Radar reflectivity charts from the Austrian radar network for 13.00 UTC. The vertical (a) west-east and (b) north-south cross sections are marked in the (c) horizontal cross section taken at a height of $2.5 \mathrm{~km}$ with two straight white lines. $\mathbf{d}$ shows the radial velocity field at a height of $2.5 \mathrm{~km}$ with greenish/reddish colours indicating movements towards/away from the radar, whose position is marked by the yellow dot
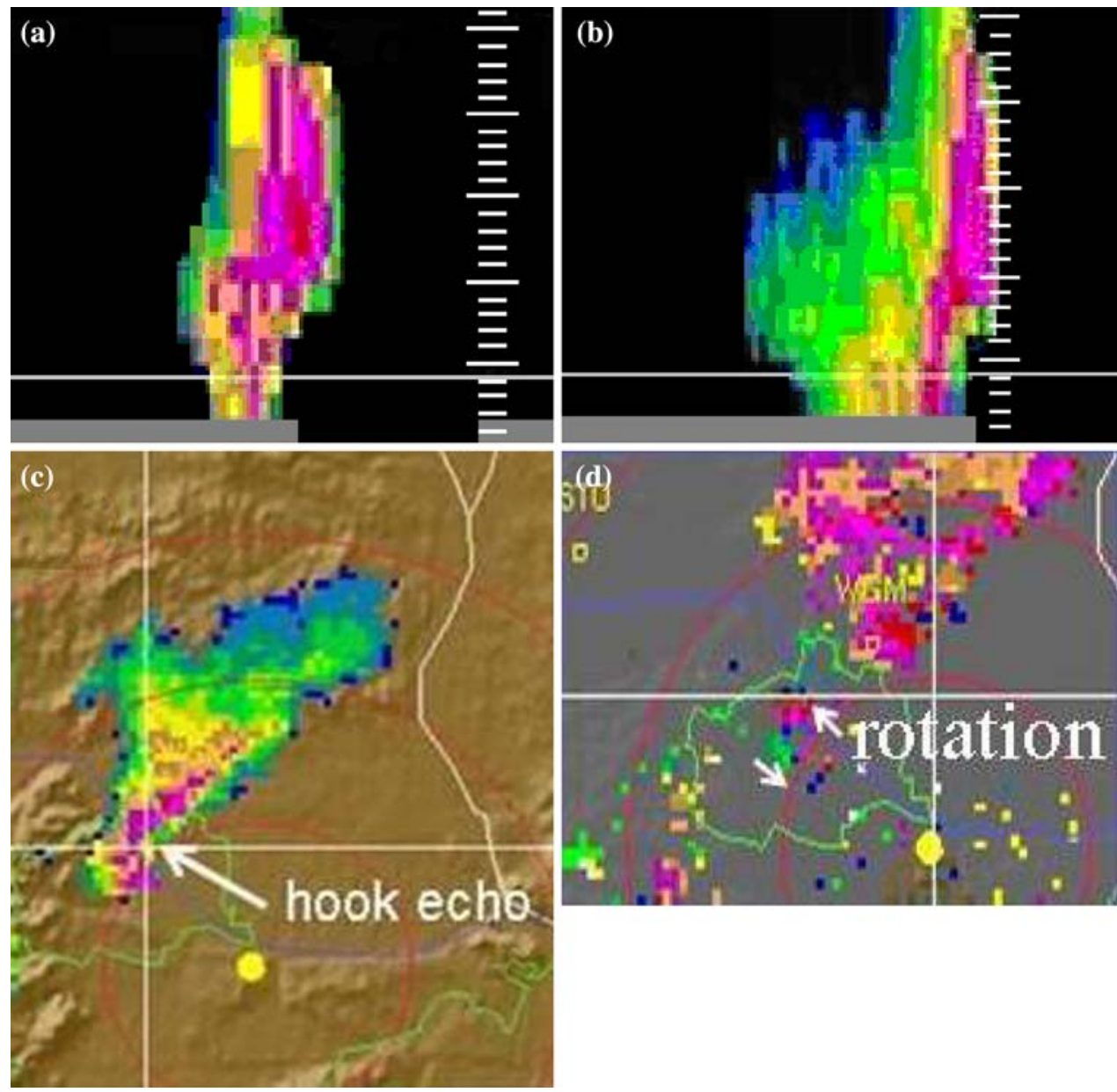
the tornado, gives strong evidence that the thunderstorm was a supercell.

The first touchdown of the tornado, rated F0 to F1 on the Fujita scale, was reported at 13.30 UTC near the Danube in Vienna. Several buildings and trees were damaged by the tornado. Additional damage was caused by the hail, which had already started before the tornadic event, with hailstone diameters of up to $6 \mathrm{~cm}$, which damaged several cars and agricultural areas. The losses amounted to six million euros in Vienna. Much worse, one casualty drowned in a flash flood and four more people were injured during the storm. The size of the hailstones of up to $6 \mathrm{~cm}$ corresponds to a fall velocity of about $30 \mathrm{~m} \mathrm{~s}^{-1}$ (Knight and Knight 2001), indicating that the intensity of the updraft has to be at least on the same order of magnitude. The occurrence of hail is a rather rare event in Vienna, with an average of appearance of 1 day per year, with the maximum in May ( 0.3 days per year) and June (0.4 days per year) (Auer et al. 2001).

Figure 13 gives the number of lightning strikes detected by the Austrian ALDIS system for 13th May 2003 with a resolution of $1 \mathrm{~km}^{2}$. These data were used to further investigate the tracking of the supercell storm. For gaining knowledge about the tornado track, the temporal resolution of the lightning data is too low, especially when taking into account that the general relationship between cloud-toground lightning strikes and tornadoes is quite controversial (MacGorman and Rust 1998), mainly for its large variability (Bechini et al. 2001). The moving path of the tornado, from west to east with a moving velocity of about
$30 \mathrm{~km} / \mathrm{h}$, with the expected track of the supercell centre is plotted (Pistotnik 2003) in Fig. 13. While crossing the river Danube, a waterspout of $5 \mathrm{~m}$ in diameter and $10 \mathrm{~m}$ in height was reported. The duration of the tornado event was less than $10 \mathrm{~min}$, as reported by storm chasers in the area (Eisler and Müller 2003). Due to the damage on the ground, the length of the tornado track was estimated to be approximately $3 \mathrm{~km}$ (Pistotnik 2003).

The last parameter investigated in this case study is precipitation. In addition to the hail and the tornado, the supercell also produced a lot of rain, with measured amounts of up to $76 \mathrm{~mm}$ in $6 \mathrm{~h}$ at Vienna Hohe Warte. The maximum daily amount of precipitation measured at that station is $78 \mathrm{~mm}$ (Auer et al. 2001) during the period from 1961 to 1990 , indicating that the event was a severe one for this region. The large amounts of precipitation caused some flash floods in the hilly north-western part of Vienna (see Fig. 13), which is also a quite rare event for this region. Further to the south of Vienna, the amount of precipitation was much lower. In Vienna downtown, $39 \mathrm{~mm}$ was reported in $24 \mathrm{~h}$; at the Vienna airport, situated south-east of Vienna, only $10 \mathrm{~mm}$ of rain was measured during this period.

\section{Conclusions}

A supercell storm including a tornado was observed over Vienna on 13th May 2003. The event was documented by storm chasers who spot such thunderstorms and can give
Fig. 13 Lightning data provided by the ALDIS system (ALDIS $\subset$ 2004,

http://www.aldis.at) for 13 th May 2003 (00.00 UTC-24.00 UTC). The resolution of the data is $1 \mathrm{~km}^{2}$. The white areas indicate regions where no strikes were detected during this day, the maximum values exceed 10 strikes per day per $\mathrm{km}^{2}$ in the northern parts of Vienna. The grey areas indicate 2 strikes day ${ }^{-1} \mathrm{~km}^{-2}$. The thick black line gives the assumed moving path of the centre of the supercell, the hatched area marked with $T$ denotes the region hit by the tornado (Pistotnik 2003). The area enclosed by the dashed line marks the region most affected by flash floods. The dotted line indicates the southern edge of the reported hail occurrence

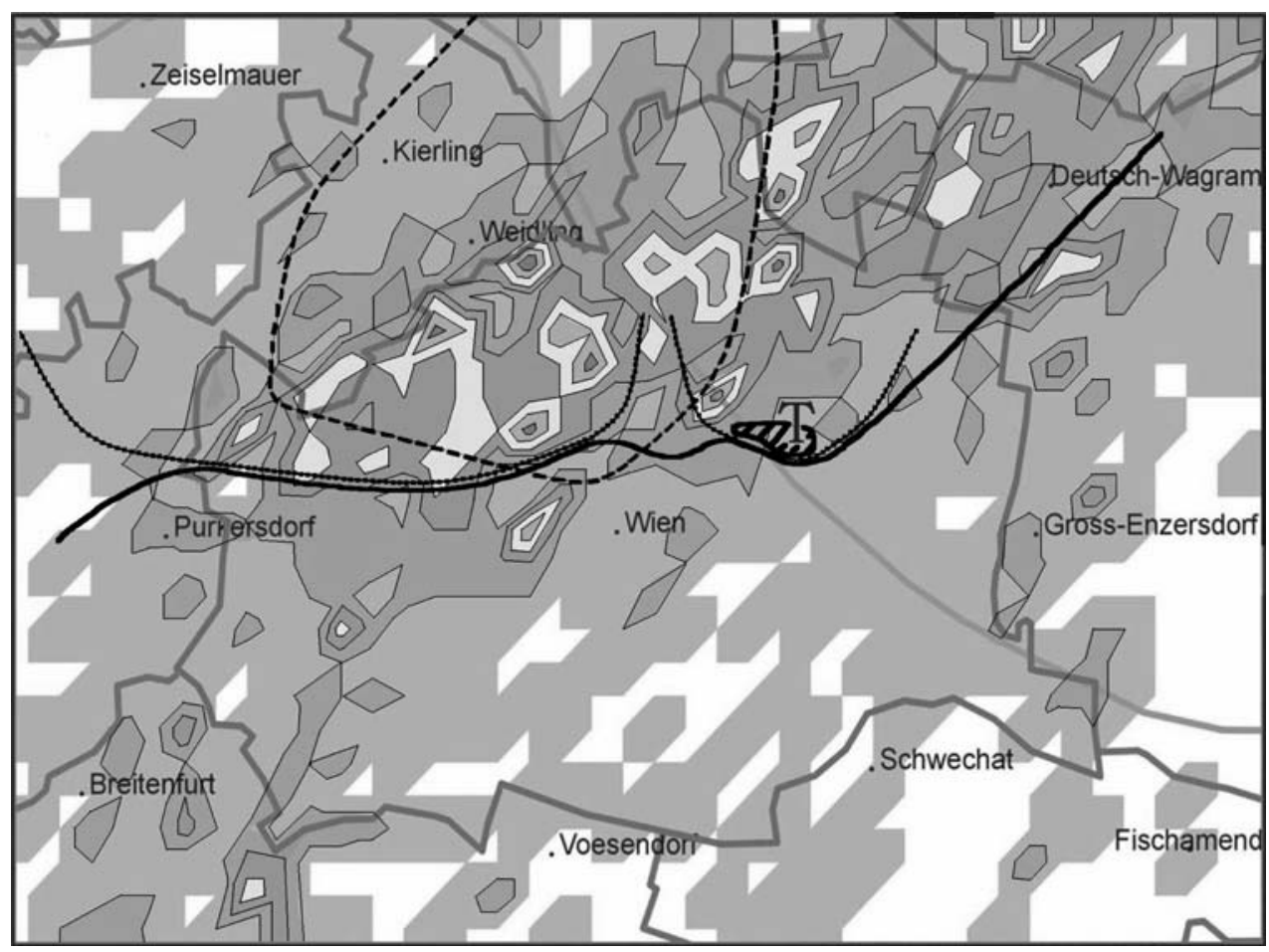


many valuable hints for the classification of the tornado. In this case, the tornado was rated as a F0 to F1 event. In addition to the storm chaser reports, many data sources have been collected to give an enclosing overview of the storm.

The storm event is interesting in a sense that the development of the storm along a pre-frontal convergence line at the northern foothills of the Alps during a low index situation with the advection of warm air masses from the Mediterranean Sea towards central Europe and the advection of cold air near the ground north of the Alps is typical for this region, but the severity of the event was rather underestimated by the forecasters. The investigations show that the combination of several parameters was necessary for triggering the tornado event:

- Precipitation in the larger Vienna area on the previous day leading to large energy consumption for evaporation

- A pre-frontal pressure rise with a south-easterly flow towards the convergence line

- Warm air advection from the south-west due to Alpine heating, leading, in addition, to the first precondition to convective inhibition

- An approaching convergence line triggering dynamically the penetration of the inversion by the moistureladen air, being stationary (predicted as a transient structure in the models) due to the Alpine foothills and the (poorly predicted) formation of a meso-low north of Vienna

- Considerable directional wind shear favouring the formation of a supercell

Furthermore, the advantages of the VERA system for the processing of real-time data with: (1) a routine data quality control, (2) an objective analysis of ground measurements with graphic output, (3) the calculation of nowcasting parameters like the moisture flux divergence and (4) the two-dimensional model comparison have been presented. Using this system, it should be possible to enlarge the time window for the nowcasting of severe weather, which would help in the prevention of disasters. To estimate the achievable advance, it will be necessary to study further events in cooperation with an operational weather service.

Acknowledgments The investigations were partially co-financed by the European Union under the INTEREG IIIB CADSES programme, contract number 3B064, project RISK-AWARE and by the FWF (Austrian Science Fund) project CONSTANCE (P19658-N10). Thanks are given to Rudolf Kaltenböck from the Austrian Aviation Weather Service (ACG) for providing information about the radar data.

Open Access This article is distributed under the terms of the Creative Commons Attribution Noncommercial License which permits any noncommercial use, distribution, and reproduction in any medium, provided the original author(s) and source are credited.

\section{References}

Auer I, Böhm R, Mohnl H, Potzmann R, Schöner W, Skomorowski P (2001) ÖKLIM-Digitaler Klimaatlas Österreichs. CD-ROM, ZAMG, Vienna, Austria

Banacos PC, Schultz DM (2005) The use of moisture flux convergence in forecasting convective initiation: historical and operational perspectives. Wea Forecasting 20:351-366

Bechini R, Giaiotti D, Manzato A, Stel F, Micheletti S (2001) The June 4th 1999 severe weather episode in San Quirino, Italy: a tornado event? Atmos Res 56:213-232

Beckman SK (1993) Preliminary results of a study on NGM low-level moisture flux convergence and the location of severe thunderstorms. In: Preprints, 17th Conference on Severe Local Storms, St. Louis, MO, October 1993, pp 138-142

Bergmann L, Schaefer C (1997) Lehrbuch der Experimentalphysik, Band 7 "Erde und Planeten." Verlag Walter de Gruyter, Berlin, Germany

Bica B, Knabl T, Steinacker R, Ratheiser M, Dorninger M, Lotteraner C, Schneider S, Chimani B, Gepp W, Tschannett S (2007) Thermally and dynamically induced pressure features over complex terrain from high-resolution analyses. J Appl Meteor Climatol 46(1):50-65

Bothwell PD (1988) Forecasting convection with the AFOS Data Analysis Program (ADAP version 2.0). In: NOOA technical memorandum WS SR-122, Fort Worth, p 92

Burgess DW, Lemon LR (1990) Severe thunderstorm detection by radar. In: Atlas D (ed) Radar in meteorology. Am Meteorol Soc, pp 619-647

Cressman GP (1959) An operational objective analysis system. Mon Wea Rev 87:367-374

Daley R (1991) Atmospheric data analysis. Cambridge University Press, Cambridge, p 457

Diendorfer G, Hofbauer F, Stimmer A (1992) The Austrian Lightning Detection and Information System-ALDIS. Configuration, organization and first results. In: Proceedings of the 21st International Conference on Lightning Protection, Berlin, Germany, September 1992

Dorninger M, Chimani B, Steinacker R, Ratheiser M (2004) Verification of mesoscale model products. In: Proceedings of the 11th Conference on Mountain Meteorology, Mount Washington Valley, NH, June 2004

Doswell CA III, Evans JS (2003) Proximity sounding analysis for derechos and supercells: an assessment of similarities and differences. Atmos Res 67-68:117-133

Dotzek N, Hannesen R, Beheng KD, Peterson RE (1998) Tornadoes in Germany, Austria and Switzerland. In: Proceedings of the 19th Conference on Severe Local Storms, Minneapolis, MN, September 1998, pp 93-96

Dotzek N, Friedrich A, Giaiotti DB, Groenemeijer P, Martin F, Stel F, Svabik O, Teittinen J (2006) Status of the European Severe Weather Database (ESWD) after one year of operational work. In: Proceedings of the 6th EMS Annual Meeting, Ljubljana, Slovenia, September 2006

Eisler H, Müller M (2003) Superzellen-Tornado-Chasing. Skywarn. Home page at: http://www.skywarn.at/

Forbes GS (1981) On the reliability of hook echoes as tornado indicators. Mon Wea Rev 109:1457-1466

Fujita TT (1981) Tornadoes and downbursts in the context of generalized planetary scales. J Atmos Sci 38:1511-1534

Galway JG (1956) The lifted index as a predictor of latent instability. Bull Amer Meteor Soc 37:528-529

Groenemeijer PH (2005) Sounding-derived parameters associated with severe convective storms in the Netherlands. MS thesis, Institute of Marine and Atmospheric research Utrecht (IMAU) 
Häberli C, Groehn I, Steinacker R, Pöttschacher W, Dorninger M (2004) Performance of the surface observation network during MAP. Meteorol Z 13(2):109-121

Hirt WD (1982) Short-term prediction of convective development using dew point convergence. In: Preprints, 9th Conference on Weather and Forecasting Analysis, Seattle, WA, June/July 1982, pp 201-205

Holzer AM (2001) Tornado climatology of Austria. Atmos Res 56:203-211

Houze RA, Schmid W, Fovell RG, Schiesser HH (1993) Hailstorms in Switzerland: left movers, right movers, and false hooks. Mon Wea Rev 121(12):3345-3370

Hudson HR (1971) On the relationship between horizontal moisture convergence and convective cloud formation. J Appl Met 10:755-762

Kaltenböck R (2004) The outbreak of severe storms along convergence lines northeast of the Alps. Case study of the 3 August 2001 mesoscale convective system with a pronounced bow echo. Atmos Res 70(1):55-75

Kaltenböck R (2005) Nowcasting of thunderstorms using mesoscale modified low level wind in Austria. In: Proceedings of the World Weather Research Program Symposium on Nowcasting and Very Short Range Forecasting, Toulouse, France, September 2005

Kann A (2001) Klimatologie konvektiver Systeme in den Ostalpen anhand von Blitzdaten. Diploma thesis, Department of Meteorology and Geophysics, University of Vienna

Kaufmann H (2006) Die mesoskalige Analyse der Feuchteflussdivergenz im Alpenraum. Diploma thesis, Department of Meteorology and Geophysics, University of Vienna

Knight CA, Knight NC (2001) Hailstorms. In: Doswell CA III (ed) Severe convective storms. AMS, vol 28, no 50, pp 223-254
MacGorman DR, Rust WD (1998) The electrical nature of storms. Oxford University Press, New York, pp 422

Negri AJ, Vonder Haar TH (1980) Moisture convergence using satellite-derived wind fields: a severe local storm case study. Mon Wea Rev 108:1170-1182

Pistotnik G (2003) Superzelle mit Tornado über Wien-ein vorläufiger Kurzbericht. Workshop zum Thema Wetterwarnungen und Extremwetterlagen in Österreich, Krumbach, May 2003

Pöttschacher W, Steinacker R, Dorninger M (1996) VERA—a high resolution analysis scheme for the atmosphere over complex terrain. MAP Newsletter 5:64-65

Steinacker R, Häberli C, Pöttschacher W (2000) A transparent method for the analysis and quality evaluation of irregularly distributed and noisy observational data. Mon Wea Rev 128:2303-2316

Steinacker R, Ratheiser M, Bica B, Chimani B, Dorninger M, Gepp W, Lotteraner C, Schneider S, Tschannett S (2006) A mesoscale data analysis and downscaling method over complex terrain. Mon Wea Rev 134(10):2758-2771

van Delden AJ (2000) The synoptic setting of a thundery low and associated prefrontal squall line in Western Europe. In: Abstracts, Conference on European Tornadoes and Severe Storms, Toulouse, France, February 2000

van Delden AJ (2001) The synoptic setting of thunderstorms in western Europe. Atmos Res 56:89-110

Waldvogel A, Federer B, Schmid W, Mezeix JF (1978) The kinetic energy of hailfalls. Part II: radar and hailpads. J Appl Met $17: 1680-1693$

Whiteman CD (2000) Mountain meteorology: fundamentals and applications. Oxford University Press, Oxford 